\title{
Fit für Fitness?
}

_ Körperliche Fitness ist ein zentrales Ziel der Physiotherapie. Warum kommen Patienten zu uns oder - leider muss ich es ja so ausdrücken - warum schicken Ärzte Patienten zu uns? Weil ihre Bewegungsmöglichkeiten und damit ihre Handlungsfähigkeiten durch Schmerzen, Verletzungen, einen akuten Krankheitsprozess oder gar eine chronische Erkrankung beeinträchtigt sind. Wir arbeiten daran, die Patienten im Rahmen ihrer Möglichkeiten und ausgerichtet an ihren Zielen wieder fit oder wenigstens fitter zu machen. Für den Alltag, den Beruf, die Freizeit.

_Und Menschen, die nicht krank sind? Oder noch nicht? Geschickt werden sie uns jedenfalls nicht. Wenn wir unsere Kompetenzen in

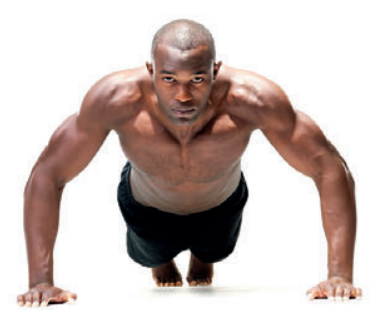

Wir kriegen Patienten fit! Sachen Prävention und Gesundheitsförderung an die Frau und den Mann bringen wollen, müssen wir uns selbst Kunden erschließen. In diesem Metier sind viele von uns nicht sehr geübt. Doch unser Bewusstsein schärft sich für dieses Arbeitsfeld. Wir sind fit für Fitnessangebote!

- Wir kennen uns aus mit Bewegung und verstehen es, sie als Heilmittel einzusetzen. Bewegung beugt aber auch Erkrankungen vor. Gesund bleiben und fit sein ist in. Gesundheit, Fitness, Wellness - ein Megatrend unserer Gesellschaft. Und ein lukrativer Markt für Fachleute, die Wohlbefinden erzeugen. Mir fällt dazu gerade ein: „Ran an den Speck!“

_ Anregung für Prävention und Sekundärprävention gibt auch die FIBO vom 11. bis 14. April 2013 in Köln. Auf der Internationalen Leitmesse für Fitness, Wellness und Gesundheit sind Physiotherapeuten die am stärksten wachsende Besuchergruppe. Die FIBO erfindet sich neu und öffnet sich mehr denn je dem Thema Gesundheit. Neu ist auch der Physiotag am Samstag (๑ S. 56 und beiliegender Flyer). Die Vorträge signalisieren ganz deutlich: Physiotherapeuten sind eine zentrale Berufsgruppe, wenn es um Fitness und Gesundheit geht.

\section{Herzlichst, Ihre}

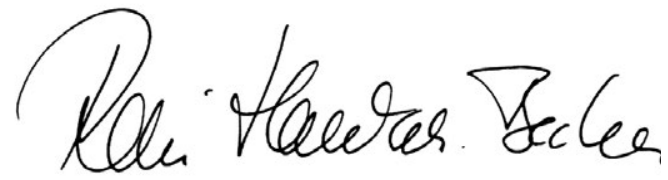

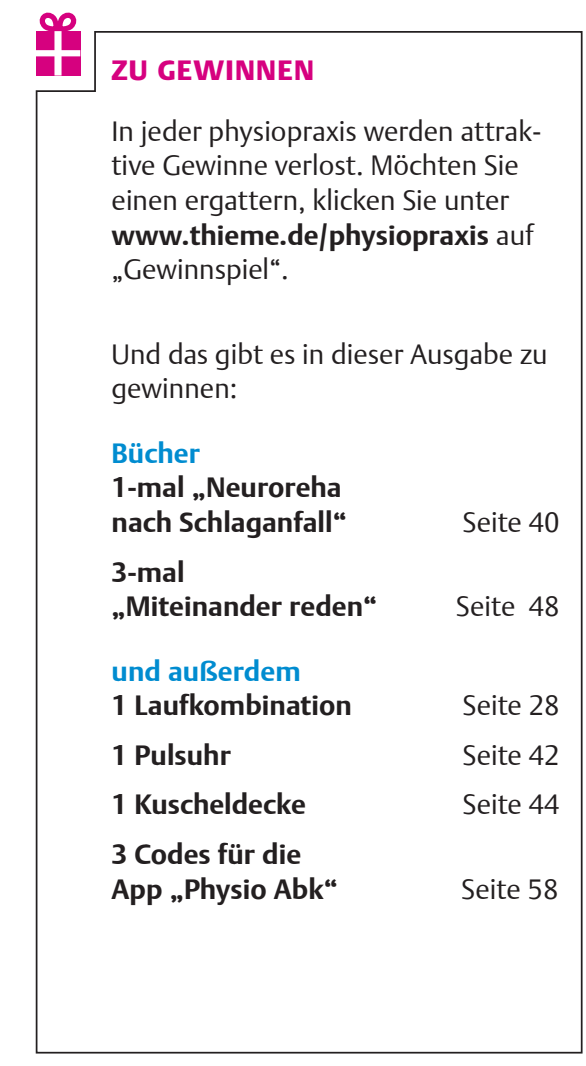

